\title{
The Effect of Synthetic Cationic Polymer Addition on Nucleation of Anaerobic Granules under Different Organic Loading Rate
}

\author{
N. Hudayah, B. Suraraksa, and P. Chaiprasert
}

\begin{abstract}
Nucleation phase with the addition of synthetic cationic polymer, polyacrylamide 8265 (MEM 8265), under different organic loading rate (OLR) was investigated. The results showed that the addition of MEM 8265 showed significant positive effects related to physico-chemical characteristics of microbial aggregates such as short nucleation time, higher size distribution of aggregates $>100 \mu \mathrm{m}$, nuclei ratio and SVI value. The nucleation phase was achieved within 69 days. The nuclei size was $126 \mu \mathrm{m}$ and nuclei ratio achieved

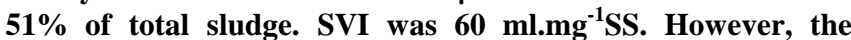
activities of acidogenic bacteria (propionic acid- and butyric acid-degrading microorganisms) and methanogens were similar to control (without polymer addition).
\end{abstract}

Index Terms-Anaerobic granules, nucleation, synthetic cationic polymer, organic loading rate.

\section{INTRODUCTION}

The formation of anaerobic granule involves multistep processes via physicochemical and biological forces resulting on the formation of multi layered granules [1], [2]. It consists several layers in which each layer is occupied by specific microorganism [3], [4]. Naturally, multilayered anaerobic granules are formed for 1-2 years of anaerobic reactor operations. According to the microbial theory, the formation of multilayered anaerobic granules are divided into two main steps namely nuclei formation (nucleation) and nuclei maturation [5], [6]. As conclusion, nucleation is considered as the main essential step and starting point for granulation.

As the development of anaerobic wastewater treatment, mass culturing of anaerobic granules is needed to provide good anaerobic granules which leads to reduce the start-up phase of industrial scale anaerobic reactor and cost of anaerobic granules seeds. However, start-up period of anaerobic reactor which is related to the formation of anaerobic granules can be approximately longer as $2-8$ months [7]. Mature granules from other reactors are normally used to shorten start-up period of anaerobic digestion.

Manuscript received June 13, 2012; revised July 15, 2012. This work was supported by the grant from Ministry of Energy of Thailand through the Joint Graduate School of Energy and Environment (JGSEE).

Nasrul Hudayah is with the Joint Graduate School of Energy and Environment (JGSEE), King Mongkut's University and Technology Thonburi (KMUTT), Thailand (e-mail: nasraul_01@yahoo.com).

Benjaphon Suraraksa is with the Excellence Center of Waste Utilization and Management (BIOTEC), Bangkok, Thailand.

Pawinee Chaiprasert is with the Division of Biotechnology, School of Bioresources and Technology, KMUTT, Bangkok, Thailand (e-mail: pawinee..cha@kmutt.ac.th).
Nevertheless, the transportation and availability of mature anaerobic granules can be drawback factors. Therefore, non-granular anaerobic was frequently used as seeding sludge for reactor since it is affordable and largely available [7]-[10].

Considering time for constructing multi layered anaerobic granules, the addition of cationic polymer had already been conducted for shortening the time of anaerobic granulation [8], [9], [11]. Hence, nucleation phase can be shortened by the addition of synthetic cationic polymer. However, there is less information which studied about the addition of cationic polymer under sludge adaptation to mixed volatile fatty acid as feeding in order to build syntroph adapted anaerobic granule nuclei. Mostly, studies of anaerobic granulation with specific enriched microorganism were conducted by combining and utilizing enriched microorganism which was previously enriched to specific substrates for several months or years before being used to start up anaerobic digestion. [12]-[14]. This research was aimed to form syntroph adapted anaerobic nuclei by the addition of synthetic cationic polymer. The adaptation of microorganism to specific substrates was concomitantly conducted during anaerobic granulation to cut the enrichment phase before start-up by stepwise increasing of the organic loading rate. Reactor performance, aggregates characteristics as well as specific microbial activity were investigated.

\section{METHODOLOGY}

\section{A. Microbial Seed and Wastewater}

Initial seed sludge was obtained from anaerobic pond of cassava wastewater treatment plant. Seed sludge was then sieved by $100-\mu \mathrm{m}$ sieving instrument resulting average initial seed sludge was approximately $46 \mu \mathrm{m}$. Wastewater used in this research was synthetic wastewater [15]. The composition of synthetic wastewater were $\left(\mathrm{NH}_{4}\right)_{2} \mathrm{SO}_{4} 132 \mathrm{mg} \cdot \mathrm{l}^{-1}$, $\mathrm{Na}_{2} \mathrm{HPO}_{4} 75.5 \mathrm{mg} . \mathrm{l}^{-1}, \mathrm{CaCl}_{2} 50 \mathrm{mg} . \mathrm{l}^{-1}, \mathrm{MgSO}_{4} 90 \mathrm{mg} . \mathrm{l}^{-1}$, yeast extract $10 \mathrm{mg} \cdot \mathrm{l}^{-1}$ and nutrient solution $0.3 \mathrm{ml}$. Mixed volatile fatty acids were used as main carbon source consisted of acetic acid, propionic acid and butyric acid (2:1:1) based on COD ratio.

\section{B. Cationic Polymer and Reactors}

Medium molecular weight polyacrylamide 8265 (MEM 8265 ) was used as synthetic cationic polymers. Optimum addition of polymers were based on results of Jar test [8], [14]. The addition of MEM 8265 was $2 \mathrm{mg} \cdot \mathrm{g}^{-1} \mathrm{SS}$. Polymer additions were arbitrarily conducted every increase of 
organic loading rate (OLR) resulting four times addition of polymers until the end of nucleation phase.

Upflow anaerobic sludge blanket reactors were used in this research with diameter $86 \mathrm{~mm}$, height $860 \mathrm{~mm}$ and working volume 4.5 liter. Sampling ports were provided along height of reactors. Recirculation line were built from up to bottom of each reactor providing high velocity circulation about $1 \mathrm{~m} \cdot \mathrm{h}^{-1}$. Reactor $(R 1)$ and reactor $(R 2)$ were for control and MEM 8625 addition, respectively.

\section{Operation Condition for Nucleation}

Nucleation phase was initiated by inoculation of seed sludge (11.44 $\mathrm{g} \mathrm{VSS} . \mathrm{l}^{-1}$ and $\left.13.17 \mathrm{~g} \mathrm{SS} . \mathrm{l}^{-1}\right)$ in all reactors. The first addition of MEM 8265 was concomitantly conducted with seed sludge inoculation. Thereafter, polymers were routinely added at every increase OLR. Reactors were operated under intermittent condition to ease adaptation of microorganism to substrate. OLR of $0.5 \mathrm{~kg}$ COD. $\mathrm{m}^{-3} \cdot \mathrm{d}^{-1}$ was firstly applied for all reactors. OLR in all reactors were stepwisely increased until $2.0 \mathrm{~kg}$ COD. $\mathrm{m}^{-3} \cdot \mathrm{d}^{-1}$. Increase of OLR was aimed to adapt microorganism to specific substrate used in this research. Circulation of wastewater was applied from top to bottom reactor with velocity of $1 \mathrm{~m} \cdot \mathrm{h}^{-1}$ to provide proper shear force for granulation. Nucleation phase under different OLR was investigated for their average diameter of aggregates, nuclei ratio and nucleation time. According to previous references, initial nuclei was classified based on its size which was range between $100-600 \mu \mathrm{m}$ [6]. Time for nuclei formation was investigated as its relationship with the increase of nuclei size. The nuclei phase was terminated until nuclei ratio achieve $\pm 50 \%$ of total sludge [10]

\section{Analysis}

$\mathrm{pH}$, alkalinity, total volatile acid (TVA) and chemical oxygen demand (COD) of influent and effluent were analyzed daily. While, suspended solid (SS), volatile suspended solid (VSS), sludge volume index (SVI) and specific methanogenic assay (SMA) were analyzed every the end of OLR. pH, alkalinity, TVA, COD, SS, SVI and VSS were analyzed based on Standard Methods [16]. Specific methanogenic and non-methanogenic activity assay were analyzed based on [17]. Microbial activity included the activities of glucose degrading microorganism, propionic and butyric acids degrading microorganism and methnogen. Glucose was analyzed using Glucose Analyzer YSI 7100 MBS. Gas chromatography (GC) Shimadzu 14B with flame ionization and thermal conductivity detector were used to analyzed volatile fatty acids (VFA) and methane concentration, respectively. Size distribution was analyzed based on image processing of MATLAB 2009. Samples of aggregate were viewed and captured by stereomicroscope Olympus SZX12. The diameter size and distribution were then analyzed by image processing of MATLAB 2009.

\section{RESULTS AND DISCUSSION}

\section{A. Reactor Performance}

Reactors operation were started at OLR $0.5 \mathrm{~kg}$ COD. $\mathrm{m}^{-3} \cdot \mathrm{d}^{-1}$ and then stepwisely increased until OLR $2.0 \mathrm{~kg}$ COD. $\mathrm{m}^{-3} \cdot \mathrm{d}^{-1}$. COD removal and ratio of TVA/alkalinity were investigated to represent reactor performance during nucleation.

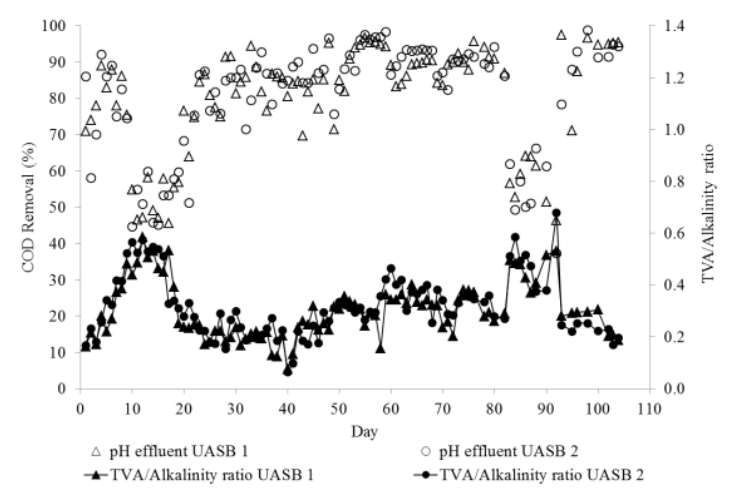

Fig. 1. Reactors performance during nucleation.

Overall reactors operation were conducted until day 104 and reactor performance shown in Fig. 1. There were decrease of COD removal and increase of TVA/alkalinity ratio which indicated the decrease of reactors performance at the beginning operation during day 11-18, COD removals were approximately $45-60 \%$. The forcing increase OLR up in short period of the acclimation of microorganism to higher OLR $1.0 \mathrm{~kg}$ COD. $\mathrm{m}^{-3} \cdot \mathrm{d}^{-1}$ probably the reason of this decrease of COD removal. After the first acclimation to higher OLR $1.0 \mathrm{~kg} \mathrm{COD} \cdot \mathrm{m}^{-3} \cdot \mathrm{d}^{-1}$ (day 10-19), reactor performance via microbial activity inside both reactors ( $\mathrm{R} 1$ and $\mathrm{R} 2)$ tend to be stable (80-90\% of COD removal) indicating the ability of microorganism to adapt with mixed VFA as main substrates. Nucleation phase was achieved at day 69 and results were described below. However, reactor performance decreased again at day 83-92 when it was exposed to OLR $2.0 \mathrm{~kg}$ COD. $\mathrm{m}^{-3} \cdot \mathrm{d}^{-1}$ followed by breakage of microbial aggregates. Therefore, OLR was recovered to OLR $1.0 \mathrm{~kg} \mathrm{COD} \cdot \mathrm{m}^{-3} \cdot \mathrm{d}^{-1}$ at day 93 which lead to stable COD removal (approximately $90 \%$ ) until end of reactors operation. TVA/alkalinity ratio can also be used to indicate reactors performance. During decrease of COD removal, TVA/alkalinity ratio in both reactors tend to increase about $0.5-0.7$. TVA/alkalinity ratio less than 0.4 indicated that anaerobic reactor could accommodate minor fluctuations of $\mathrm{pH}$ and more than 0.4 indicated that the instability of anaerobic reactor could be expected [18].

\section{B. Biomass Inside Reactors}

VSS were investigated to represent microbial biomass concentration inside reactors. Seed sludge was initially inoculated into reactors with $11.44 \mathrm{~g} . \mathrm{l}^{-1}$ of VSS and $13.17 \mathrm{~g} . \mathrm{l}^{-1}$ of SS resulting on VSS/SS ratio 0.87. VSS at the end of

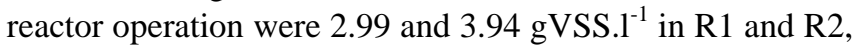
respectively. These severe decrease of VSS were most likely caused by sampling, microbial wash out and slow growth of anaerobic microorganism. The generation time of butyric and propionic acid-degrading microorganism was about 2.3 days and 4.6 - 5.8 days, respectively [19], [20]. While, acetoclastic methanogens had generation time approximately 10 times longer than acidogenic microorganism. Therefore, three of those microorganisms are slow-growing microorganisms. Biomass concentrations inside reactors depend on the dominant type of microorganism. The dominant microorganism in this research was propinic acid- 
and butyric acid-degrading microorganism and methanogens since the substrate used was mixed VFA of acetic, propionic and butyric acids. High OLR also contributed to decrease of biomass inside reactors due to high gas production which lead to increase of hydrodynamics inside reactors.

\section{Size Distribution of Microbial Aggregates}

The main objective of this research was to built initial nuclei of anaerobic granules. Zheng, et.al. [6] defined granule nuclei as aggregates with a diameter of $100-600 \mu \mathrm{m}$. Size distribution of microbial aggregates in R1 and R2 were shown in Fig. $2 \mathrm{a}$ and $2 \mathrm{~b}$, respectively.

a) Size distribution in R1

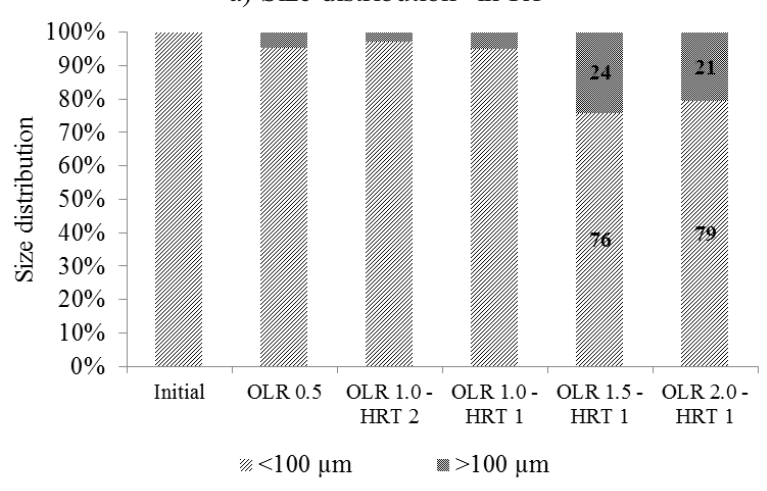

b) Size distribution in R2

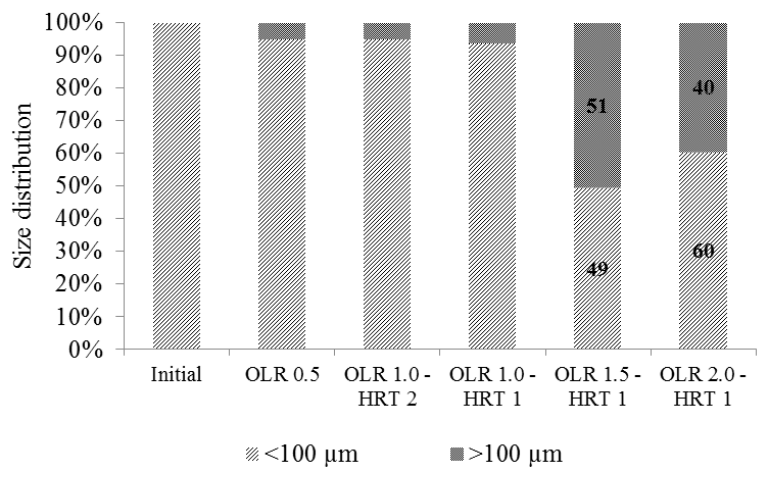

Fig. 2. Size distribution in $R 1$ (a) and $R 2$ (b).

Fig. 2 shows sharp increase of aggregates $>100 \mu \mathrm{m}$ at OLR $1.5 \mathrm{~kg}$ COD. $\mathrm{m}^{-3} \cdot \mathrm{d}^{-1}$ in both reactors. OLR affected on size distribution results as shown in Fig. 2a for R1 or reactor control. The size distribution of aggregates $>100 \mu \mathrm{m}$ were about less than $10 \%$ from initial until the end of OLR $1.0 \mathrm{~kg}$ COD. $\mathrm{m}^{-3} \cdot \mathrm{d}^{-1}$ before it sharply increased as $24.06 \%$ at the end of OLR $1.5 \mathrm{~kg} \mathrm{COD} \cdot \mathrm{m}^{-3} \cdot \mathrm{d}^{-1}$ (day 69). However, it decreased when OLR was increased to $2.0 \mathrm{~kg}$ COD. $\mathrm{m}^{-3} \cdot \mathrm{d}^{-1}$. It seemed that hydrodynamics inside of reactor changed due to gas production from high OLR. Therefore, it could be concluded that OLR $1.5 \mathrm{~kg}$ COD. $\mathrm{m}^{-3} \cdot \mathrm{d}^{-1}$ showed as the best OLR for nucleation with adaptation to mixed VFA. In $R 2$ (Fig. 2b), the size distribution also showed similar tendency with R1. However, the difference between $R 1$ and $R 2$ was shown at the end of OLR $1.5 \mathrm{~kg} \mathrm{COD} \cdot \mathrm{m}^{-3} \cdot \mathrm{d}^{-1}$ in which size distribution of aggregates $>100 \mu \mathrm{m}$ was more than $50 \%$ (end of nucleation). From result of $R 2$, it can be seen that synthetic polymer MEM 8625 showed significant effect for fastening nucleation phase. Cationic polymers contributes for their cation or positive ion which can balance negative ion surrounded microorganism. As result, the repulsion force among microorganism reduced then microorganism tend to aggregate each other to form aggregates or initial granules [8], [9], [11], [21].

\section{Mean Aggregates Size}

Increase of mean aggregates size were also observed in both reactors during nucleation phase (Fig. 3). Stable mean aggregates size were shown from initial until OLR $1.0 \mathrm{~kg}$ COD. $\mathrm{m}^{-3} \cdot \mathrm{d}^{-1}$ operation. Then, sharp increase or mean aggregates size occured from OLR $1.0 \mathrm{~kg} \mathrm{COD} \cdot \mathrm{m}^{-3} \cdot \mathrm{d}^{-1}$ to 2 $\mathrm{kg}$ COD. $\mathrm{m}^{-3} \cdot \mathrm{d}^{-1}$. At day 69 (nucleation phase), aggregates in $\mathrm{R} 2$ showed higher mean aggregates size as $126 \mu \mathrm{m}$ compared to aggregates in $R 1$ as $72 \mu \mathrm{m}$. However, mean aggregates size in both reactors at the end of OLR $2.0 \mathrm{~kg} \mathrm{COD} \cdot \mathrm{m}^{-3} \cdot \mathrm{d}^{-1}$ tend to decrease due to high gas production at high OLR which possibly contributed to change the hydrodynamics condition inside reactors.

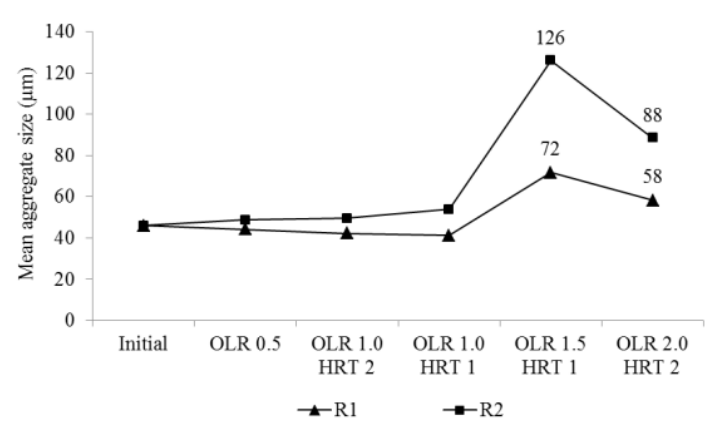

Fig. 3. Mean aggregates size in $R 1$ and $R 2$ reactors.

\section{E. Nuclei ratio}

Nuclei ratio was used to represent sludge size and nucleus content. It was defined as the ratio of nuclei to total sludge [10]. In initial microbial seed, the seed sludge from anaerobic pond of cassava wastewater treatment plant was treated by sieving with $100 \mu \mathrm{m}$ instrument resulting microbial aggregates size $<100 \mu \mathrm{m}$ (average $46 \mu \mathrm{m}$ ).

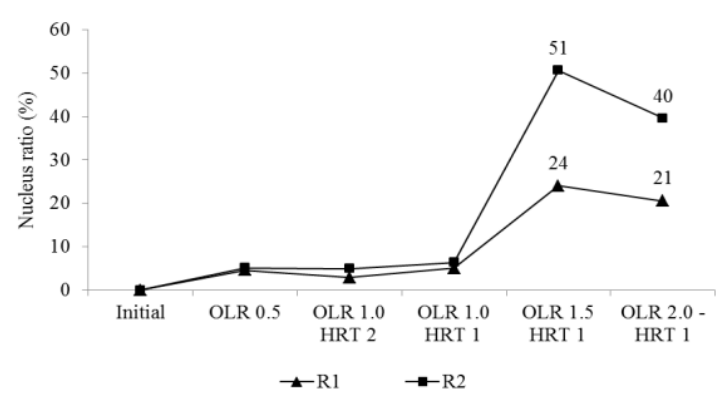

Fig. 4. Nuclei ratio of aggregates in $R 1$ and $R 2$ reactors.

From Fig. 4, it can be seen that nuclei ratio in both reactors were less than $10 \%$ until the end of OLR $1.0 \mathrm{~kg} \mathrm{COD} \cdot \mathrm{m}^{-3} \cdot \mathrm{d}^{-1}$ and thereafter, it sharply increased at the end of OLR $1.5 \mathrm{~kg}$ COD. $\mathrm{m}^{-3} \cdot \mathrm{d}^{-1}$ (day 69 ). R2 showed higher nuclei ratio as $51 \%$ than in $R 1$. The results showed the effect of synthetic polymer MEM 8265 for shortening nucleation phase. Wu, et.al. [10] found that nuclei ratio of $47 \%$ at day 146 in UASB reactor under favorable hydrodynamic condition. The results of size distribution, mean aggregates and nuclei ratio showed similar tendencies in which at OLR $2.0 \mathrm{~kg}$ COD. $\mathrm{m}^{-3} \cdot \mathrm{d}^{-1}$, the microbial aggregates showed decreasing of physical characteristics such as decrease of mean aggregates size and nuclei ratio. Higher OLR could possibly produce more gas resulting higher hydrodynamic condition inside reactor 
which lead on the disturbances of microbial aggregates inside reactors [10].

\section{F. Sludge Volume Index (SVI)}

Sludge volume index (SVI) represents the volume of sludge in $\mathrm{ml}$ to settle under current time (normally 30 minutes) with unit of $\mathrm{ml}$ settled sludge per $\mathrm{mg}$ suspended solids $\left(\mathrm{ml} . \mathrm{g}^{-1}\right.$ SS). Low SVI value is for better settling characteristics of granule and high SVI value is normally found at non-granular inoculums with poor setting characteristics. SVI value of initial seed sludge used in this research is very low as 76 $\mathrm{ml} . \mathrm{g}^{-1} \mathrm{SS}$. The reference SVI values of granules are about 10 $-20 \mathrm{ml} . \mathrm{g}^{-1} \mathrm{SS}$ [22], [23] and flocculent sludge is about 20 $40 \mathrm{ml} \cdot \mathrm{g}^{-1} \mathrm{SS}$ [24].

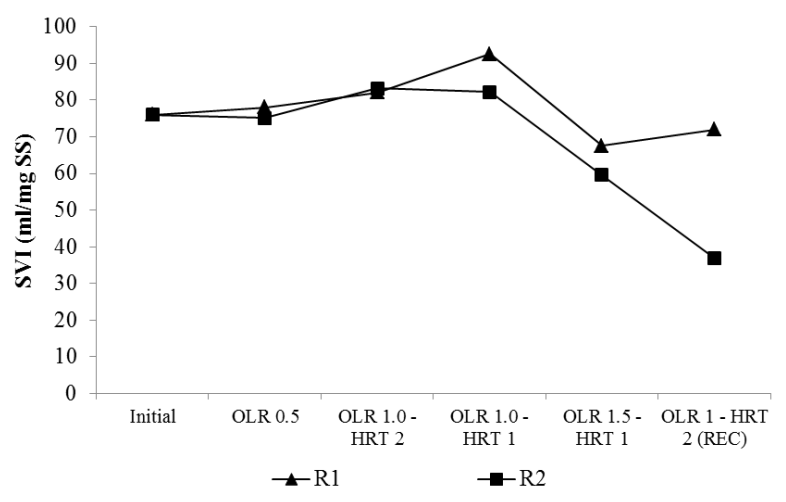

Fig. 5. Sludge volume index of aggregates in $R 1$ and $R 2$ reactors

Fig. 5 shows that decrease of SVI was found after operation of OLR $1.0 \mathrm{~kg}$ COD. $\mathrm{m}^{-3} \cdot \mathrm{d}^{-1}$. The addition of synthetic polymer MEM 8265 showed significant effect for reducing SVI value since SVI of aggregates R1 tend to increase after being exposed to high OLR $2.0 \mathrm{~kg} \mathrm{COD} \cdot \mathrm{m}^{-3} \cdot \mathrm{d}^{-1}$.

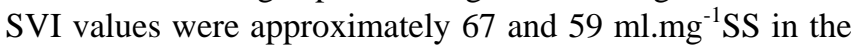
end of OLR $1.5 \mathrm{~kg} \mathrm{COD} \cdot \mathrm{m}^{-3} \cdot \mathrm{d}^{-1}$ (day 69) for aggregates R1 and $\mathrm{R} 2$, respectively.

\section{G. Specific Microbial Activity}

Adaptation of microorganism to mixed VFA during nucleation phase was conducted to produce syntroph adapted granules nuclei. Syntroph microorganism related to hydrogen producers and consumers microorganism. Therefore, the activities of propionic acid -, butyric acid - degrading microorganism and methanogen were investigated. However, the activity of glucose-degrading microorganism was needed to be observed since this microorganism was important for nuclei maturation.

The activity of glucose - degrading microorganism in this research was used to represent the activity of acidogens microorganism. This microorganism is important for the maturation step by its ability to produce extracellular polymer (ECP) for enhancing the granulation process. Although the substrate used in the nucleation phase is mixed VFA, the glucose-degrading microorganism is still active and their activity slightly decreased.

Fig. 6 shows that the activity of glucose - degrading microorganism in $R 1$ and $R 2$ reactors tend to decrease along the increase of OLR and decrease of HRT. This can be explained since the main substrate for feeding reactor is mixed VFA (acetic, propionic and butyric acids). However, the decrease of the activity of glucose - degrading microorganism were not too distant. The end of OLR $1 \mathrm{~kg}$ COD. $\mathrm{m}^{-3} \cdot \mathrm{d}^{-1}$ (recovery; REC) of $R 2$ showed the most decrease of activity as 0.6 fold lower than initial activity. It can be concluded that although mixed VFA was used as main substrate, the glucose - degrading microorganism is still active. It means the maturation phase of granule nuclei can be conducted since the substrate for maturation phase is glucose and the growth of glucose - degrading microorganism is fast (as its generation time about 1.4 hours) [25]

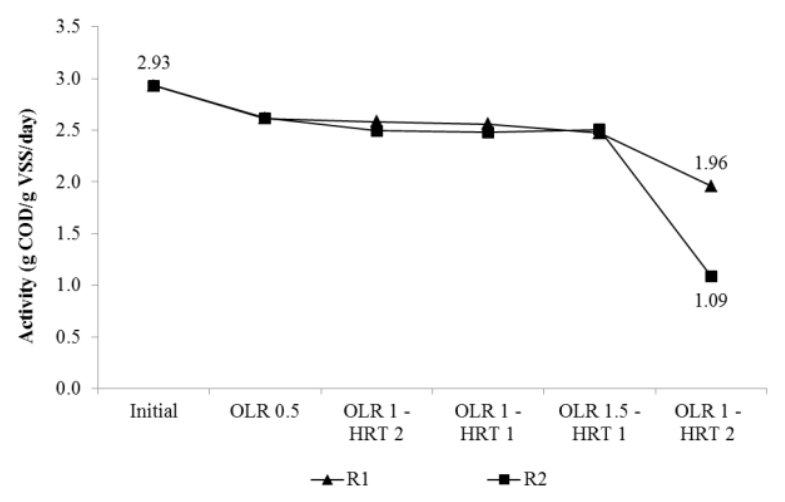

Fig. 6. The activity of glucose-degrading microorganism.

Butyric acid - degrading microorganism plays important role in acetogenic phase to degrade butyric acid (one of intermediate products in anaerobic digestion), as well as propionic acid - degrading microorganism which degrades propionic acid to acetic acid. Butyric acid is degraded to be 2 molecules of acetic acids. The activity of butyric acid degrading microorganism can be seen in Fig. 7.

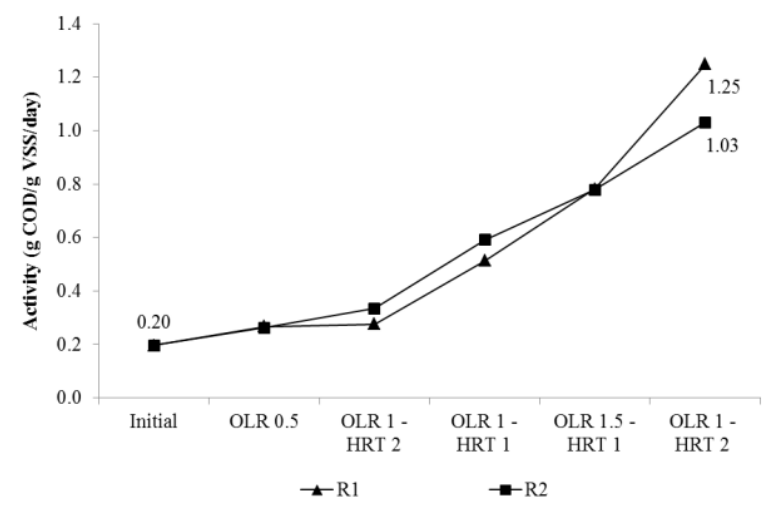

Fig. 7. The activity of butyric acid-degrading microorganism.

The activity of butyric acid - degrading microorganism increased along the increase of OLR. It seemed that the adaptation of initial microorganism with mixed VFA was successful. The highest increase of activity was shown by R1 and R2 at the end of OLR $1.5 \mathrm{~kg}$ COD. $\mathrm{m}^{-3} \cdot \mathrm{d}^{-1}$ and HRT 1 day as $0.78 \mathrm{~g} \mathrm{COD.g}{ }^{-1}$ VSS. $\mathrm{d}^{-1}$ or 4 -fold higher than initial microorganism activity for degrading butyric acid. After recovery, the activity of butyric acid-degrading microorganism still increased as 1.25 and $1.03{\mathrm{~g} \mathrm{COD} . \mathrm{g}^{-1} \text { VSS.d }}^{-1}$ in $R 1$ and $R 2$, respectively.

Propionic acid - degrading microorganism is also one of synthroph microorganism in acetogenic phase of anaerobic digestion. Propionic acid - degrading microorganism utilizes intermediate products of anaerobic digestion (propionic acid) to produce acetate acid. The increase of the activity of propionic acid - degrading microorganism during reactors 
operation was not sharp as the increase of the activity of butyric acid - degrading microorganism. The highest increase of its activity was found at $R 2$ at the end of OLR 1.5 $\mathrm{kg} \mathrm{COD} \cdot \mathrm{m}^{-3} \cdot \mathrm{d}^{-1}$ and HRT 1 day which was twice higher (from $0.24 \mathrm{~g} \mathrm{COD.g} \mathrm{g}^{-1}$ VSS.d $\mathrm{d}^{-1}$ as initial activity to $0.52 \mathrm{~g}$ COD. $\mathrm{g}^{-1} \mathrm{VSS} . \mathrm{d}^{-1}$ ) from initial activity (Fig. 8). It also can be concluded that the adaptation of mixed VFA substrate increased the activity of syntroph microorganism namely butyric-and propionic-degrading microorganism. The activity of propionic acid-degrading microorganism also increased after recovery condition as 1.14 and $0.86 \mathrm{~g}$ COD. $\mathrm{g}^{-1}$ VSS. $\mathrm{d}^{-1}$ in $R 1$ and $R 2$, respectively.

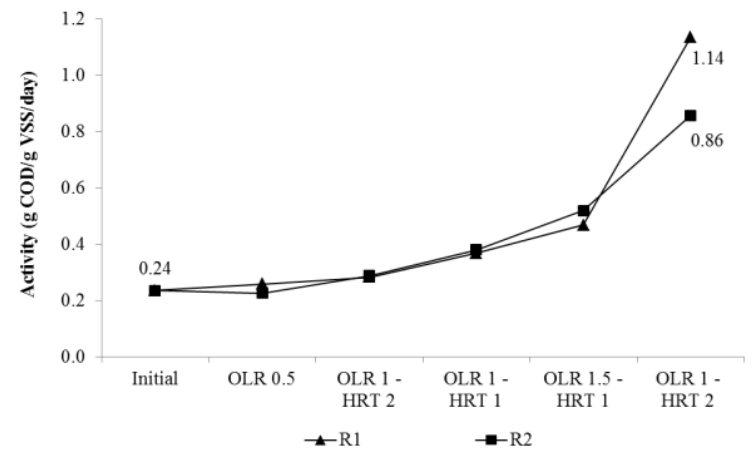

Fig. 8. The activity of propionic acid-degrading microorganism

Acetoclastic methanogens utilizes acetic acid to produce methane and carbon dioxide as final products of anaerobic digestion. Methanogen is always considered as the most sensitive microorganism in anaerobic digestion system. It can be seen from Fig. 9 above that the methanogen activity tend to decrease at OLR 0.5 and then during the time, the activity of methanogens increased. R1 showed the highest decreases of methanogen activity which were approximately 0.6- and 0.3 -fold decrease from intial methanogen activity at operating condition of OLR $0.5 \mathrm{~kg}$ COD. $\mathrm{m}^{-3} \cdot \mathrm{d}^{-1}$ and OLR 1 $\mathrm{kg}$ COD. $\mathrm{m}^{-3} \cdot \mathrm{d}^{-1}$ with HRT 2 days. These results related with the results of reactor performance in which there were acids accumulation, i.e., acetic and propionic acids, at the middle of those operating conditions. The accumulation of acetic acid in the system was high since propionic and butyric acids were main substrates which were degraded into acetic acid by syntroph microorganism. Moreover, methanogens is the most sensitive to the environmental condition compared to other microorganism groups. The highest increase of methanogen microorganism of $0.18 \mathrm{~g} \mathrm{COD} . \mathrm{g}^{-1} \mathrm{VSS} . \mathrm{d}^{-1}$ was found in $R 2$ as 1.5 times higher than initial activity. However, methanogen activity in all reactors slightly increased during reactor operation.

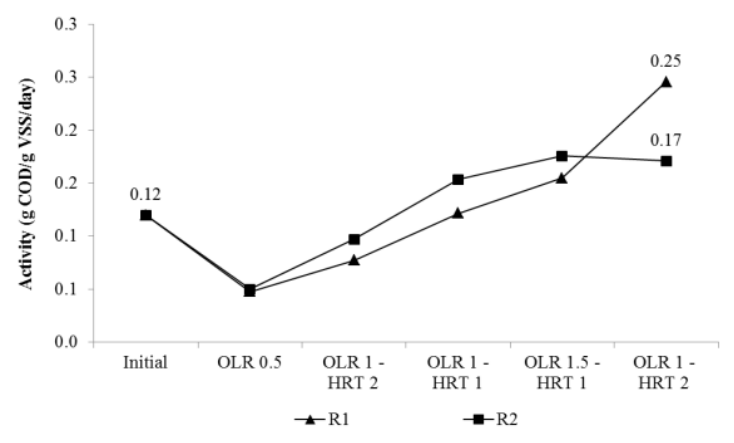

Fig. 9. The activity of methanogens.
From the activity results, it can be concluded that microbial aggregates in $R 2$ reactor with addition of synthetic polymer MEM 8265 closed to control reactor (no polymer addition), except at the end of reactor operation. Slightly decrease of microbial activity in $R 2$ compared to $R 1$ was found. Therefore, it is needed to be elucidated the factor affecting the microbial activity in $R 2$ such as the optimum dose of MEM 8265 addition.

\section{CONCLUSIONS}

Addition of synthetic polymer MEM 8265 showed significant positive effects related to physico-chemical characteristics of microbial aggregates such as short nucleation time, higher size distribution of aggregates $>100$ $\mu \mathrm{m}$, nuclei ratio and SVI value. However, the microbial activity of aggregates $R 2$ showed slight lower activity compared to control reactors. This may be caused by the additional dose of synthetic cationic polymer excess at the end of reactor operation which probably lead to toxicity or disintegrate of microbial aggregates. Therefore, it is needed to investigate the optimum polymer addition for anaerobic granulation.

\section{ACKNOWLEDGMENT}

The authors would like to thank The Ministry of Energy of Thailand for the research grant through The Joint Graduate School of Energy and Environment (JGSEE), King Mongkut's University of Technology Thonburi (KMUTT), Thailand.

\section{REFERENCES}

[1] Y. Liu and J.-H. Tay, "State of the art of biogranulation technology for wastewater treatment," Biotechnology advances, 2004. vol. 22, no. 7, pp. 533-563.

[2] L. W. Hulshoff Pol, et al., "Anaerobic sludge granulation," Water Research, 2004, vol. 38, pp. 6, pp. 1376-1389.

[3] D. J. Batstone, J. Keller, and L. L. Blackall, "The influence of substrate kinetics on the microbial community structure in granular anaerobic biomass," Water Research, 2004, vol. 38, no. 6, pp. 1390-1404.

[4] H. Satoh, et al., "Layered structure of bacterial and archaeal communities and their in situ activities in anaerobic granules," Appl. Environ. Microbiol., 2007, vol. 73, no. 22, pp. 7300-7307.

[5] Y. Liu, et al., "Mechanisms and models for anaerobic granulation in upflow anaerobic sludge blanket reactor," Water Research, 2003, vol. 37, no. 3, pp. 661-673.

[6] D. Zheng, L. T. Angenent, and L. Raskin, "Monitoring granule formation in anaerobic upflow bioreactors using oligonucleotide hybridization probes," Wiley Subscription Services, Inc., A Wiley Company. 2006, pp. 458-472.

[7] W. Zhou, et al., "Triggering forces for anaerobic granulation in UASB reactors," Process Biochemistry, 2006, vol. 41, no. 1, pp. 36-43.

[8] R. El-Mamouni, R. Leduc, and S. R. Guiot, "Influence of synthetic and natural polymers on the anaerobic granulation process," Water Science and Technology, 1998, vol. 38, no. 8-9, pp. 341-347.

[9] K. Y. Show, et al., "Accelerated start-up and enhanced granulation in upflow anaerobic sludge blanket reactors," Water Research, 2004, vol. 38 , pp. $2293-2304$

[10] J. Wu, et al., "Impacts of hydrodynamic shear force on nucleation of flocculent sludge in anaerobic reactor," Water Research, 2009, vol. 43, no. 12, pp. 3029-3036.

[11] P. Bhunia and M. M. Ghangrekar, "Effects of cationic polymer on performance of UASB reactors treating low strength wastewater," Bioresource Technology, 2008, vol. 99, no. 2, pp. 350-358.

[12] R. El-Mamouni, et al., "Characterization of different microbial nuclei as potential precursors of anaerobic granulation," Journal of Biotechnology, 1995, vol. 39, no. 3, pp. 239-249. 
[13] R. El-Mamouni, R. Leduc, and S. R. Guiot, "Influence of the starting microbial nucleus type on the anaerobic granulation dynamics," Apply Microbiologu Biotechnology, 1997, vol. 47, pp. 189 - 194.

[14] A. M. Resmanto, "Granulation of substrate-adapted microorganism with cationic polymer addition," in Biotechnology. 2010, King Mongkut's University of Technology Thonburi.

[15] G. J. F. Smolders et al., "Model of the anaerobic metabolism of the biological phosphorus removal process: Stoichiometry and $\mathrm{pH}$ influence,"Wiley Subscription Services, Inc., A Wiley Company. pp. 461-470, 1994

[16] APHA, Standard method for the examination of water and wastewater. APHA/AWWA/WEF, ed. 21. 2005, Washington, D.C.: APHA/AWWA/WEF.

[17] M. Soto, R. Méndez, and J. M. Lema, "Methanogenic and non-methanogenic activity tests. Theoretical basis and experimental set up," Water Research, 1993, vol. 27, no. 8, pp. 1361-1376.

[18] E. Behling et al., "Domestic wastewater treatment using a UASB reactor," Bioresource Technology, 1997, vol. 61, no. 3, pp. 239-245.

[19] W. Gujer and A. J. B. Zehnder, "Conversion processes in anaerobic digestion," Water Science and Technology, 1983, vol. 15, no. 1, pp. $127-167$.
[20] S. Ghosh and F. G. Pohland, "Kinetics of Substrate Assimilation and Product Formation in Anaerobic Digestion," Journal Water Pollution Control Federation, 1974, vol. 46, no. 4, pp. 748-759

[21] S. Uyanik, P. J. Sallis, and G. K. Anderson, "The effect of polymer addition on granulation in an anaerobic baffled reactor (ABR). Part I process performance," Water Research, 2002, vol. 36, no. 4, pp. 933-943

[22] M. M. Ghangrekar, S. R. Asolekar, and S. G. Joshi, "Characteristics of sludge developed under different loading conditions during UASB reactor start-up and granulation," Water Research, 2005, vol. 39, pp. $1123-1133$

[23] Y. G. Yan and J. H. Tay, "Characterisation of the granulation process during UASB start-up," Water Research, 1997, vol. 31, no. 7, pp. 1573-1580.

[24] G. Lettinga et al., "Use of the upflow sludge blanket (USB) reactor concept for biological wastewater treatment, especially for anaerobic treatment," Biotechnology and Bioengineering, 1980, vol. 22, no. 4, pp. 699-734.

[25] G. Dinopoulou, R. M. Sterritt, and J. N. Lester, "Anaerobic acidogenesis of a complex wastewater: II. Kinetics of growth, inhibition, and product formation," Biotechnology and Bioengineering, 1988, vol. 31, no. 9, pp. 969-978 